\title{
Modeling of Air Pollutant Dispersion in Street Canyons in Cross-Wind
}

\author{
Ibrahim A. M. Gad ${ }^{*}$, Mofreh. M. Nasief* , Salem S. Abdel Aaziz ${ }^{*}$ and Alaa A. Osman ${ }^{* *}$
}

\begin{abstract}
A study of vehicle exhaust dispersion within different street canyons models in an urban ventilated by cross-wind is conducted at this work to investigate how pollution dispersion is affected by wind speed, building height to width ratios, street and building geometries, and canyon street number. For all cases, cars exhaust was represented by a line source emitting $\mathrm{CO}_{2}$ and pollution dispersion was studied in two and three dimensions, airflow and the street canyons were assumed thermally isolated. The FLUENT Computational Fluid Dynamics (CFD) software package has been used with a standard k- $\varepsilon$, RNG k- $\varepsilon$ and sstk- $\omega$ turbulence models to simulate different street canyon models. For all models, the results show a vortex appearance within the street canyon, with updrafts near the upwind buildings and down-draft near the downwind buildings. In the transverse vertical plane at mid-canyon show that the pollutant concentrations has higher concentrations at the leeward face than that at the windward faces, and has higher concentrations above downwind buildings than that above upwind buildings, Longitudinal distributions of pollutant concentrations at leeward and windward faces show decreasing of the concentration with increasing building height. For multi-street models, the pollutant concentrations increase for higher order street in wind direction. The pollutant concentration results were compared with Meroney et al. ${ }^{[9]}$ experiments. Also a series of flow visualization and static pressure coefficient measurements were performed in the smoke tunnel and wind tunnel to compared with the numerical study.
\end{abstract}

Keywords: street canyons, Air Pollutant, vehicle exhaust

\section{Introduction}

Air quality in urban areas has great importance for the health of living people. But all sources of air pollutant reduce the air quality. Exhaust of motor vehicles including automobiles, trucks, and trains is one of the major sources of air pollutant. A lot of studies were performed to explain the contribution of each major source of air pollution that affects the air quality in urban area. In 2005 The Egyptian Environmental Affairs Agency (EEAA) ${ }^{[1]}$ have been evaluated the annual percentage of the amount of air pollution of each air pollutant source to the total annual load of air pollution in street canyons of Great Cairo and concluded that; solid municipal waste burning in the open air, exhaust of motor vehicles, industrial emissions, and, open burning of the agriculture waste have $36 \%, 26 \%, 32 \%$ and $6 \%$ respectively. Add to this the high growth rate of the number of vehicles in Egypt with time which have already exceeded 3.5 million vehicles in 2005 and increases $10 \%$ annually, especially if we take into account the fact that in Egypt a large number of vehicles are not scraped before the lapse of three folds of their presumed productive age.

\footnotetext{
${ }^{*}$ Department of Power Mechanical Engineering, Faculty of Engineering, Zagazig University.

*** Egyptian, Armed Forces
} 
Thus exhaust of motor vehicles seems to be one of the two most danger sources of air pollution in the street canyon not only in great Cairo but also in major cities because; 1) it touches all people in their homes, shops, streets and so on; 2) it cannot be avoided like the industrial emissions which can be translated out of the city.

The air pollution may cause serious illness, an increase in mortality and a potential hazard to human health as any substance which may harm humans, animals or vegetation Castanas, Kampa ${ }^{[2]}$ and Curtis et al. ${ }^{[3]}$. The air pollution is also affecting the economic costs due to adverse health effects and non-human health effects, Xin Deng ${ }^{[4]}$. Their studies resulting that air pollution creates a large amount of non-human health related economic costs including reduced visibility, building and vehicle damage, and harm to many types of plants and animals.

Baldasano et al. ${ }^{[5]}$ collect the information of the air quality from large cities and found that, the worldwide trend is to reduce the concentrations of pollutants. Imposing strong restrictions by local governments and international organizations is needed. Developed countries have made great efforts to improve air quality by demanding emission and air quality regulations, continuous air quality monitoring in urban and industrial centers, and use of cleaner fuels such as natural gas. Imposing strong restrictions by local governments and international organizations is necessary. However, in poor countries and those with low average incomes, concentrations of air pollutants remain high. The trend will be the elevation of their living or ground levels as they develop, making the problem even worse.

In the last decade a lot of studies were performed to determine the pollutant concentration and the major factors that affects on the transport and dispersion of the pollutants that's emitted in the street canyon which must be designed carefully to minimize the pollutant concentration in the street canyon. Xiaomin et al. ${ }^{[6,7]}$ and Georgios and Nicolas ${ }^{[8]}$ used a different street canyon configurations and different roof shapes respectively to denote the vortices and characteristics of pollutant dispersion in street canyons. They found that the pollutant transport is strongly dependent upon the type of flow regime and the vortex structure inside the canyon which mainly depends on the street layout and the roof shapes. Meroney et al. ${ }^{[9]}$ and Gomes et al. ${ }^{[10]}$ used atmospheric boundary layer wind tunnel to study the pollutant dispersion for a 2-D and 3-D models respectively. From the experimental work they found that inside the urban canyon when a stable rotating vortex develops the street ventilation is reduced, and pollution is trapped inside the canyon. Simoens et al. ${ }^{[11]}$ performed some measurements of the scalar dispersion of smoke released from a 2-D slot in the midway between two square obstacles to measure simultaneously the velocity and scalar concentration of the pollution. From the study it's observed that, for all canyon openings a primary vortex was formed and driven by the external flow above it. The Reynolds shear stress above the canyon is negative for all openings. The vertical region where the negative stress level is high becomes wider with increasing canyon opening width, and penetrates into the canyon.

A small region of positive stress just above the upstream obstacle is seen for all canyon openings. Gromke and Ruck ${ }^{[12]}$ study the Influence of trees on the dispersion of pollutants in an urban street canyon they modeled the trees with spherical crowns and positioned inside the street canyon, varying crown diameter, crown permeability, trunk height and tree spacing. Concentrations were measured at the facades of the street canyon. Increasing crown diameters led to increasing concentrations at the leeward street canyon wall. For some cases, a variation of trunk height led to a modification of the concentration pattern on the walls. Also increasing the tree spacing resulted in a noticeable concentration decrease. 
Recently CFD models have been increasingly used to simulate the dispersion of pollution in an urban street canyon models taking in account the influence of buildings-street geometry and other characteristics.

Kambiz and Goodarz ${ }^{[13]}$, John Crowther et al. ${ }^{[14]}$, Wang et al. ${ }^{[15]}$, Savory et al. ${ }^{[16]}$ and Moussiopoulos et al. ${ }^{[17]}$ used the software packages; FLUENT, PHOENICS and CHENSI to solve the Reynolds Stress Transport. These software packages use a standard k- $\varepsilon$ turbulence model to simulate the airflow and pollution transport in a 2-D and 3-D street canyon models with different aspect ratio (building width/height) $\mathrm{w} / \mathrm{h}$. The simulations showed that a vortex was formed within the street canyon. Contours of pollutant concentrations showed pollutants circulating within the vortex, the gaseous pollutants concentration on the leeward walls of the buildings are much higher than those on the windward walls. In addition, when reduce the canyon aspect ratio, the wind speed close to the cavity ground will reduce, that increase the poor ventilation qualities. The building height and building arrangement are important factors for pollutant dispersion.

Sabatino et al. ${ }^{[18,19]}$ used the standard $\mathrm{k}-\varepsilon$ turbulence model and the advection-diffusion method for the CFD simulations to compare with the operational model (atmospheric dispersion model ADMS-Urban) by simulating the pollutant dispersion from point and line sources in the atmospheric boundary layer within different regular building geometries. The analysis shows that, the overall CFD simulations produce similar concentration to those predicted by the operational approach. However, some differences are based on appropriate selection of the grid resolution, surface roughness, inlet conditions, turbulence and dispersion models and turbulent Schmidt number when using the CFD model such as FLUENT for atmospheric dispersion. Leung et al. ${ }^{[20]}$ was developed a 2-D renormalized-group RNG k- $\varepsilon$ turbulence model to calculate the air exchange rate of idealized street canyons and the complicated flow structures inside street canyons by using the FLUENT 6.1 code. The outputs was validated against other modeling (large-eddy simulation, k- $\varepsilon$ ) and wind tunnel results and found a slight over prediction but the deviation was less than $20 \%$. Coirier et al. ${ }^{[21]}$ was made a transport and dispersion modeling by solving an Eulerian transport equation using the velocity and turbulence field found from the steady Reynolds-Averaged NavierStokes (RANS) solution. A validation study has been undertaken that compares computed to measured velocity, turbulence and dispersion data for the neutrally stable flows in a series of water tunnel and wind tunnel experiments.

Louka et al. ${ }^{[22]}$, Xiaomin et al. ${ }^{[23]}$ and Savory et al. ${ }^{[24]}$ performed a numerical study investigate the thermal effects on the airflow within a street canyon, which are produced by the variation of direct solar heating of the street sides and ground, based on the experimental and numerical simulations using the CHENSI and FLUENT code which solve the standard k- $\varepsilon$ turbulence model and Renormalized Group RNG k- $\varepsilon$ turbulence model. It was observed that a thin thermal layer develops locally within a few centimeters from the heated wall leads to make the convective flow close to the windward wall carries air masses from the street level to upwards where normally cleaner air is transported.

The plan of present work is to investigate in two and three-dimensional models air flow, pressure distribution, concentration and dispersion of pollutant around buildings in street canyons models, and parameter affecting them like as cross wind speed, building height to width ratios, street and building geometries, and canyon street number. The k- $\varepsilon$ model was used in the simulation which compared with the available wind tunnel experiments and the flow visualization in smoke tunnel. 


\section{Numerical simulation}

Different models of street canyons are numerically treated. In 2-D study, two models are treated; first one street canyon model identical to that of Meroney et al ${ }^{[9]}$, and second is a multi-street canyon model having 10 successive street canyon with the same square building cross-section and aspect ratio equal 1 . While in 3-D study street canyons models with number of cubic buildings in various arrangements are treated.

The governing equations controlling the solution are partial differential equations for, mass, momentum and species transport of turbulent airflow which are written in Cartesian tensor notations in general form as follows:

$\frac{\partial \rho}{\partial t}+\frac{\partial u_{i}}{\partial x_{i}}=0$

$\rho \frac{\partial u_{i}}{\partial t}+\rho \frac{\partial}{\partial x_{j}}\left(u_{j} u_{i}+\overline{u_{i}^{\prime} u_{j}^{\prime}}\right)=-\frac{\partial P}{\partial x_{i}}+\frac{\partial}{\partial x_{i}}\left(\tau_{i j}\right)$

$\frac{\partial C^{\alpha}}{\partial t}+u_{j} \frac{\partial C^{\alpha}}{\partial x_{j}}=\frac{\partial}{\partial x_{j}}\left(\left(D^{\alpha}+\frac{v_{t}}{S c_{t}}\right) \frac{\partial C^{\alpha}}{\partial x_{j}}\right)$

Where $u_{i}$ and $P$ are the fluid mean velocity and pressure, $u_{i}$ is the fluctuating velocity, $\rho$ represents fluid density, and $v$ is the kinematics viscosity. In Equation (3) $C^{\alpha}$ is the concentration of pollutant species $\alpha$ and $\mathrm{D}^{\alpha}$ is its diffusivity, $v_{t}$ is the turbulence eddy viscosity, and $\mathrm{Sc}_{\mathrm{t}}$ is turbulence Schmidt number.

The term $\rho \overline{u_{i}^{\prime} u_{j}^{\prime}}$ in Equation (2) is the time-averaged rate of momentum transfer due to turbulence. The Reynolds stress tensor $\tau_{i j}=-\overline{u_{i}^{\prime} u_{j}^{\prime}}$ is given by

$\overline{u_{i}^{\prime} u_{j}^{\prime}}=-\frac{\mu_{t}}{\rho}\left(\frac{\partial u_{i}}{\partial x_{j}}+\frac{\partial u_{j}}{\partial x_{i}}\right)+\frac{2}{3} k \delta_{i j}$

The turbulent kinetic energy $\mathrm{k}$ is defined as half the trace of the Reynolds stress tensor such that

$k=\frac{1}{2} \sqrt{\overline{u_{i} u_{j}}}$

To determine the turbulent velocity and the length scales, the k- $\varepsilon$ model (two equation model) is used that's solves one transport equation for turbulent kinetic energy $\mathrm{k}$ and another for dissipation rate $\varepsilon$ and written as

$$
\begin{aligned}
& \rho \frac{D k}{D t}=\frac{\partial}{\partial x_{j}}\left[\left(\mu+\frac{\mu_{t}}{\sigma_{k}}\right) \frac{\partial k}{\partial x_{j}}\right]+\mu_{t} S^{2}-\rho \varepsilon \\
& \rho \frac{D \varepsilon}{D t}=\frac{\partial}{\partial x_{j}}\left[\left(\mu+\frac{\mu_{t}}{\sigma_{\varepsilon}}\right) \frac{\partial \varepsilon}{\partial x_{j}}\right]+\frac{\varepsilon}{k}\left(C_{1 \varepsilon} \mu_{t} S^{2}-\rho C_{2} \varepsilon\right)
\end{aligned}
$$


The sstk- $\omega$ model on the other hand, has the capability of addressing some of the deficiencies of the k- $\varepsilon$ model by solving the standard k equation but uses specific dissipation rate $\omega$ as a length-determining factor and written as

$$
\begin{aligned}
& \rho \frac{D k}{D t}=\tau_{i j} \frac{\partial U_{i}}{\partial x_{j}}-\rho \beta^{*} f_{\beta^{*}} k \omega+\frac{\partial}{\partial x_{j}}\left[\left(\mu+\frac{\mu_{t}}{\sigma_{k}}\right) \frac{\partial k}{\partial x_{j}}\right] \\
& \rho \frac{D \omega}{D t}=\alpha_{\omega} \frac{\omega}{k} \tau_{i j} \frac{\partial U_{i}}{\partial x_{j}}-\rho \beta^{*} f_{\beta^{*}} k \omega^{2}+\frac{\partial}{\partial x_{j}}\left[\left(\mu+\frac{\mu_{t}}{\sigma_{k}}\right) \frac{\partial k}{\partial x_{j}}\right] \\
& \mu_{t}=\rho c_{\mu} \frac{k^{2}}{\varepsilon}, \quad \varepsilon=\beta^{*} \omega k
\end{aligned}
$$

The set of constants for the above equations are summarized in Table 1 according to Launder and Spalding ${ }^{[25]}$.

Table 1 Coefficient of k- $\varepsilon$ equations

\begin{tabular}{|c|c|c|c|c|}
\hline \hline $\mathrm{C}_{\mu}$ & $\sigma_{\mathrm{k}}$ & $\sigma_{\varepsilon}$ & $\mathrm{C}_{1}$ & $\mathrm{C}_{2}$ \\
\hline 0.09 & 1.0 & 1.3 & 1.44 & 1.92 \\
\hline \hline
\end{tabular}

In this work the flow is assumed to be a steady flow, so the unsteady term in the governing equations is equal to zero.The velocity inlet boundary condition, for wind inlet (first inlet) and vehicle exhausts inlet (second inlet) are used. The first inlet (incoming wind velocity) has an atmospheric boundary layer which used $1 / 7^{\text {th }}$ power law inlet velocity profile with average speed $\mathrm{U}_{\infty}$. Three average reference wind speed $\mathrm{U}_{\infty}=3,5,7 \mathrm{~m} / \mathrm{s}$ are used, in the secondary inlet a mixture of $\mathrm{CO}_{2}$ and air enter the canyon at the midline in the ground and secondary inlet enters the exhausts $\left(\mathrm{Co}_{2}\right.$ and air) at volumetric fluxes $\dot{Q}_{c_{n z}}=4 \mathrm{lh}$ and $\dot{Q}_{\text {air }}=100 \mathrm{l} / \mathrm{h}$ that's the same values used by Meroney et al. ${ }^{[9]}$ experiments. Dimensionless form of pollutant concentrations $K=\left(\mathrm{CU}_{\infty} h\right) /\left(Q_{C_{g 2}} / l\right)$ is the main judgment parameter needed to be calculated; $\mathrm{C}$ is the volume fraction of pollutant, $\mathrm{h}$ is the building height, and $\hat{Q}_{c_{n z}} / l$ is the emission source strength per unit length. For outlet flow, an outflow boundary condition was assumed. The top surfaces in models and two vertical side surfaces in 3-D models are assumed to be a plane of symmetry. The ground of the domain and building walls are defined as walls with non slip velocity and zero diffusive flux.

Fig. 1 - a shows the computational grid of the domain for a one street canyon model in 2-D which is chosen geometrically identical to the experiment of Meroney et al. ${ }^{[9]}$. The points 1,2 , $3, \ldots, 13,14$ are points of determination of K Fig. $1-$ b. In the multi-street model having ten parallel street canyons with buildings in both sides of the same square cross-section and $\mathrm{w} / \mathrm{h}$ $=1$, is numerically tested Fig 2 . In the cases; $U_{\infty}=3,5$, and, $7 \mathrm{~m} / \mathrm{s}$

The computational domain is discrete by a grid generated from GAMBIT ${ }^{\mathrm{TM}}$ preprocessor code. Unstructured grids of triangular cells were generated and used in the computation which is identical to Kambiz and Goodarz ${ }^{[13]}$ study, the grid density was denser near the wall to improve the results accuracy. This grid resolution is selected following a detailed sensitivity study so that an optimization of computational time and accuracy is achieved. The multispecies models of FLUENT ${ }^{\mathrm{TM}}$ code were used and the flow field and pollution concentration in the canyons were evaluated. 


\section{Experimental setup}

\subsection{Flow visualization}

The installation used for flow visualization in this study ${ }^{[26]}$, composed of: smoke tunnel having vertical test section, video camera, video, personal computer and oak capture utility program. This installation has a unique advantage of variable slow-motion playback, still framing, and slow motion reverse playback allowing a detailed and clear picture of the flow patterns.

The smoke tunnel is made of steel sheets, and is mounted vertically on a steel trolley as seen in Fig. 3. The flow is induced by means of a variable speed fan motor at the top of the tunnel. The working section is $180 \mathrm{~mm}$ wide, $240 \mathrm{~mm}$ height, and $100 \mathrm{~mm}$ deep. Models are attached to the rear wall of the working section while the front wall is of clear acrylic and readily movable. Smoke is introduced by a comp located below the working section that emits twenty-three stream of smoke at $7 \mathrm{~mm}$ center distances. The working section is brightly illuminated from both sides by test section light. The air flow velocity in working section may be varied from zero to about $5 \mathrm{~m} / \mathrm{s}$.

\subsection{Wind tunnel measurement}

The wind tunnel used in present measurements is of the open circuit type of horizontal test section. The test section built in the present work of wood and acrylic having $160 \mathrm{~cm}$ long, $90 \mathrm{~cm}$ high and $15 \mathrm{~cm}$ wide while the straighter built of thin sheet metal having $15 \mathrm{~cm}$ length and $2 \mathrm{~cm} \times 2 \mathrm{~cm}$ cell dimension. One and two street canyon model is fabricated with high accuracy from acrylic 2-D with aspect ratio equal 1 with height equal $15 \mathrm{~cm}$ Fig.4. Four holes (pressure taps), for each surface of the building model are pierced longitudinally in the mid span line in flow direction. The static pressure is measured using an electronic manometer. The static pressure coefficient $C_{p}=\left(p-p_{a t m}\right) / 0.5 \rho V^{2}$ distribution was calculated for three values average wind speed; 3,5 , and $7 \mathrm{~m} / \mathrm{s}$.

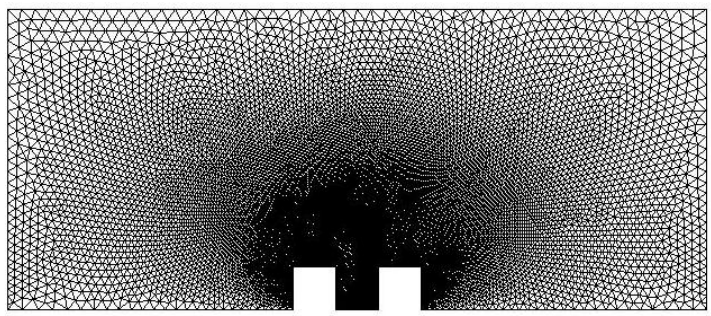

(a) computational grid

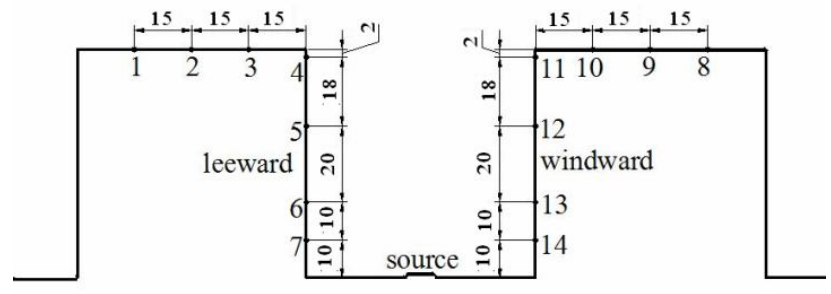

(b) positions of points of calculated $\mathrm{K}$

Fig. 1 One street canyon model

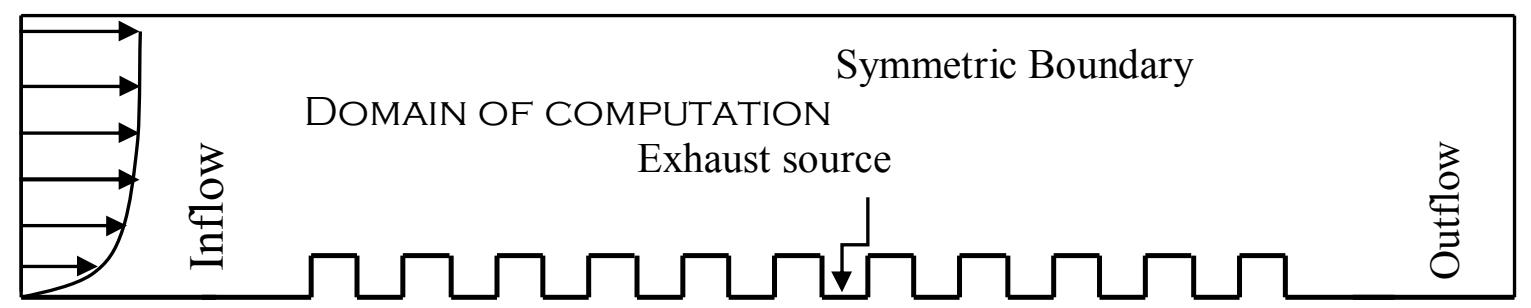

Fig. 2 multi-street model having ten parallel street canyons

$6 / 13$ 


\section{Results and discussion}

In two and three dimensional domains, effects of different parameters on vehicle exhausts dispersion within different street canyons models in cross-wind were investigated in this work. Wind speed, buildings geometries and arrangements, and order of street number in street canyon are the parameters of study. In 2-D model one street canyon which is chosen geometrically identical to the experiment of Meroney et al. ${ }^{[9]}$ Was visualized in smoke tunnel with smoked speed $U_{\infty}=3 \mathrm{~m} / \mathrm{s}$ Fig. 5-a. The model is numerically tested for flow pattern (velocity vector) Fig. 5-b, by k- $\varepsilon$ model, shear stress transport k- $\omega$ (sstk- $\omega$ ), and the RNG k- $\varepsilon$ models, while $\mathrm{C}_{\mathrm{p}}$ and $K$ are calculated, the dimensionless $K$ is calculated by all the above techniques in, leeward wall, windward wall, upstream building roof, and downstream building roof and compared at Fig. 6 through a, b, c, and d. It's found that, the dimensionless concentration $\mathrm{K}$ doesn't change significantly with different wind approach velocities. Also k- $\varepsilon$ appears in good agreement at low wind speed to predict the non-dimensional concentration $\mathrm{K}$ near walls in comparison with other turbulence models, and overestimates the nondimensional concentration $\mathrm{K}$ at high wind speeds. RNG k- $\varepsilon$ shows a reasonable agreement with experiments at leeward and windward wall where the sstk- $\omega$ appears underestimates the experiments at leeward and wind ward wall and in reasonable agreements at upstream and downstream building roof.

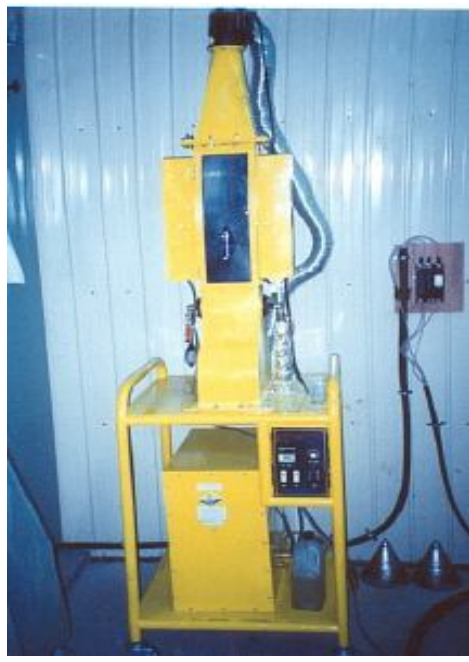

Fig. 3 The smoke tunnel

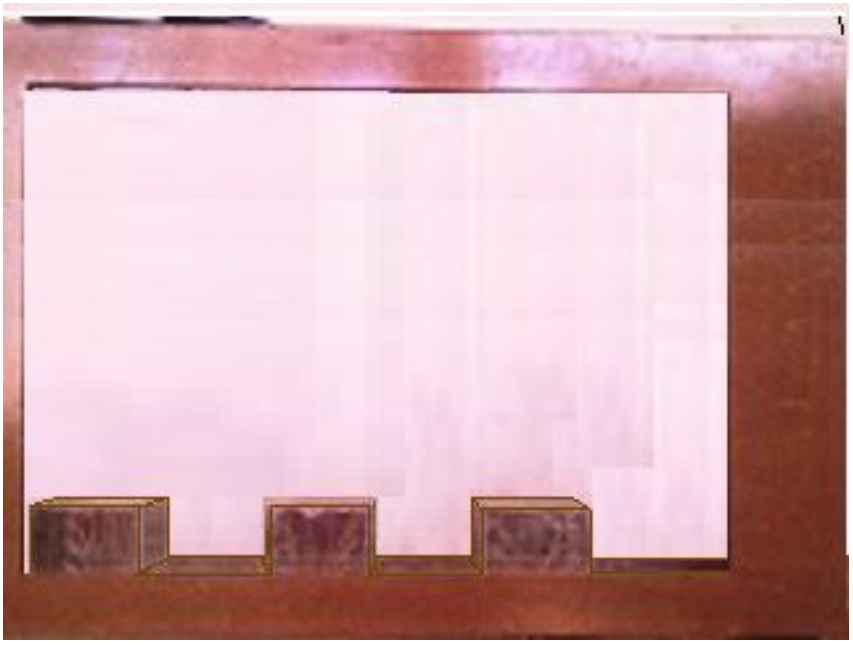

Fig. 4 Wind tunnel test section

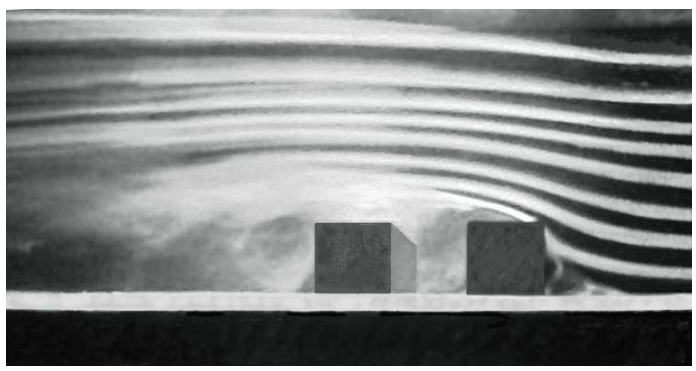

a) visualization

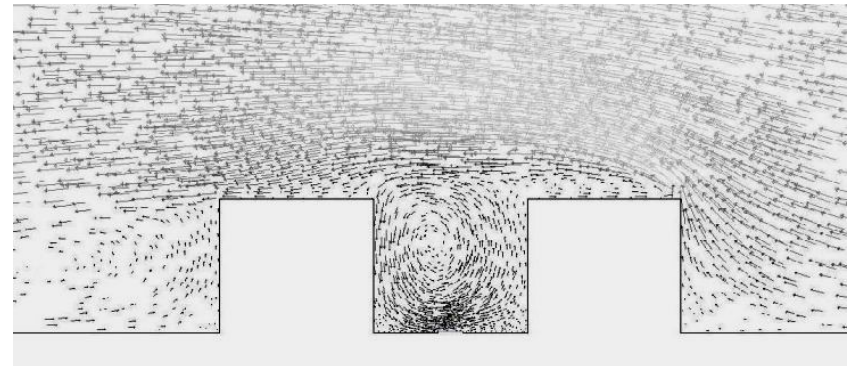

b) numerical simulation

Fig. 5 Flow pattern around one street canyon model 

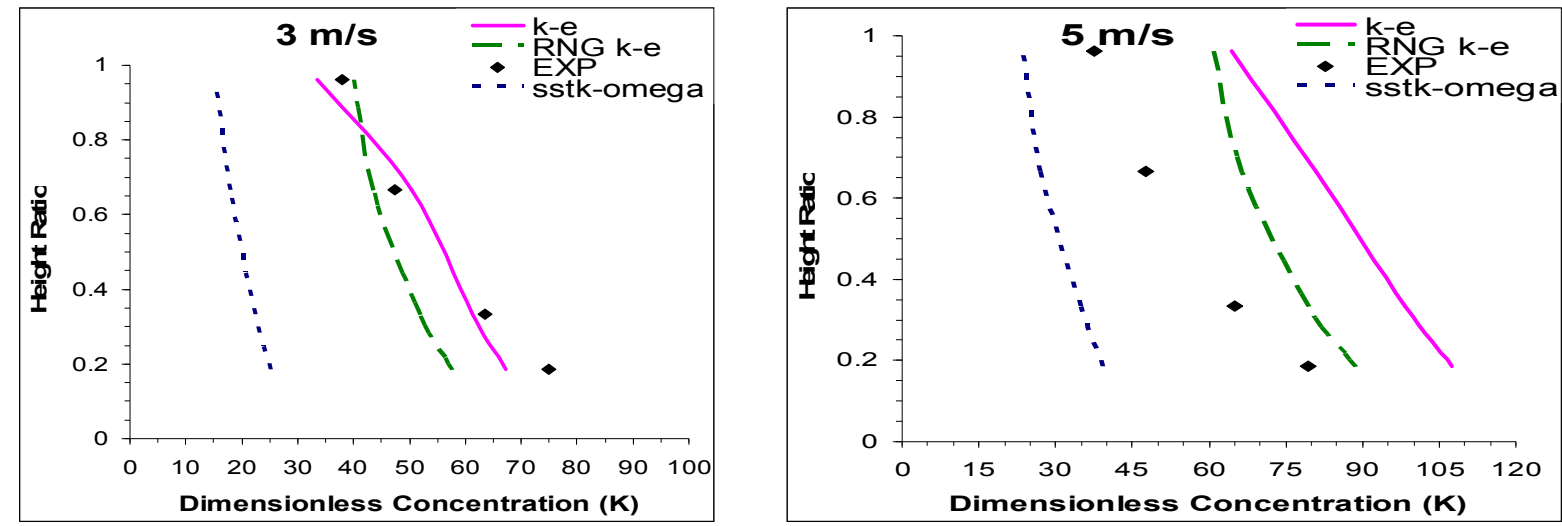

(a) leeward wall
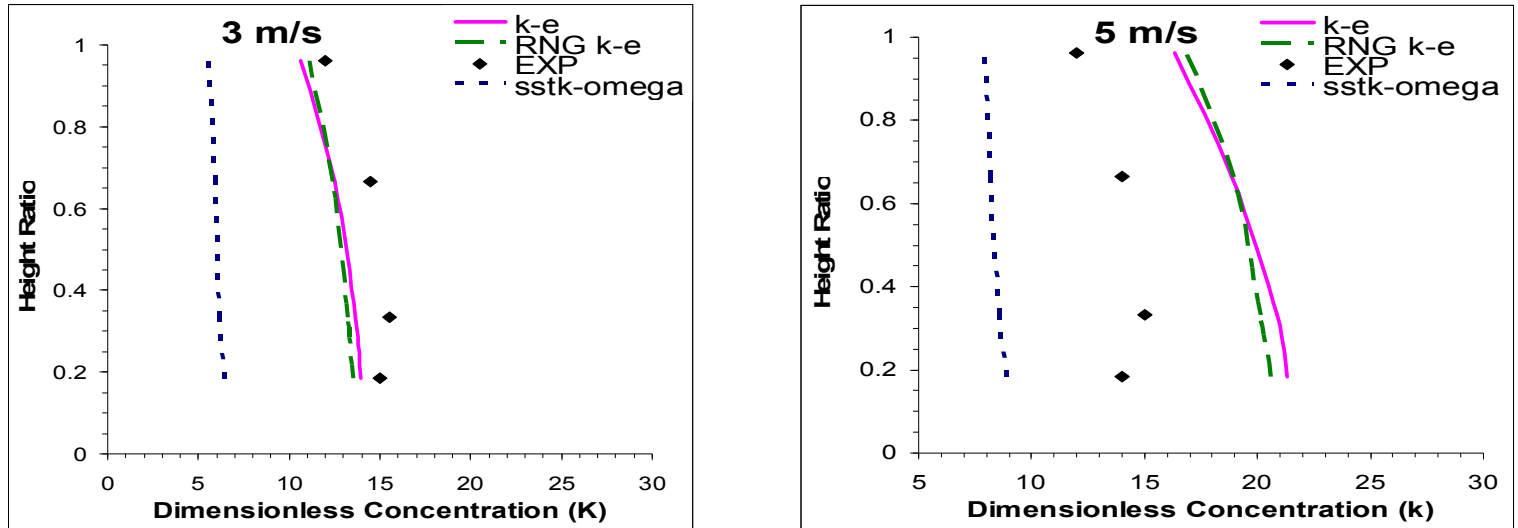

(b) windward wall
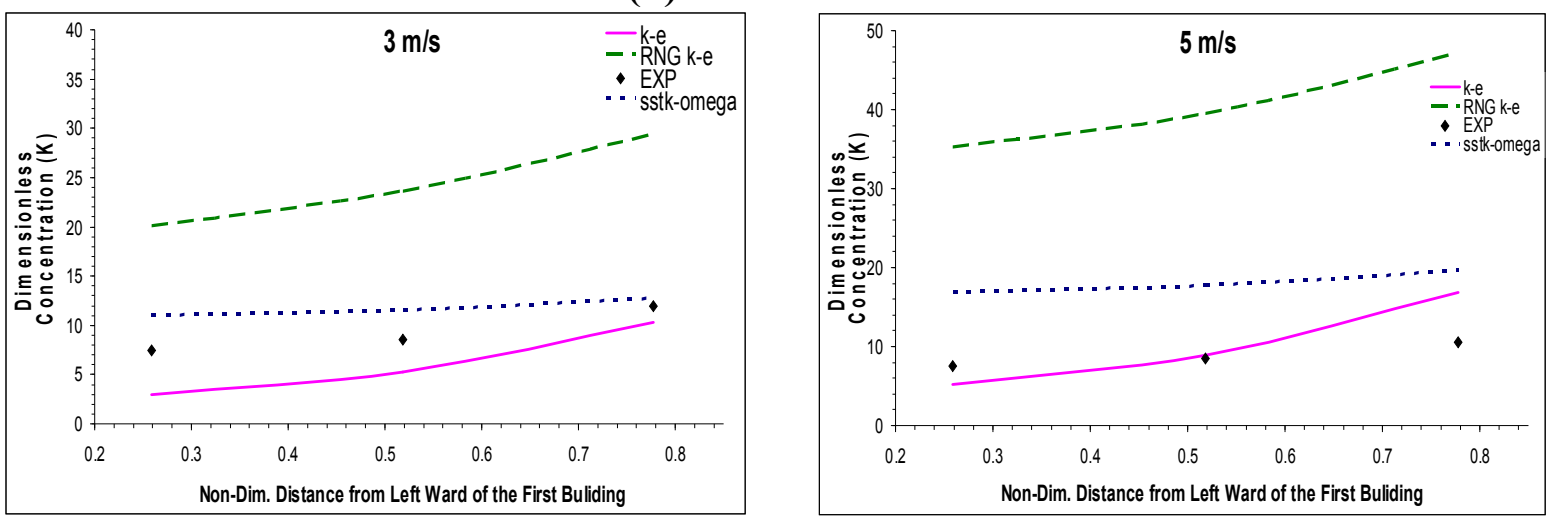

(c) upstream building roof
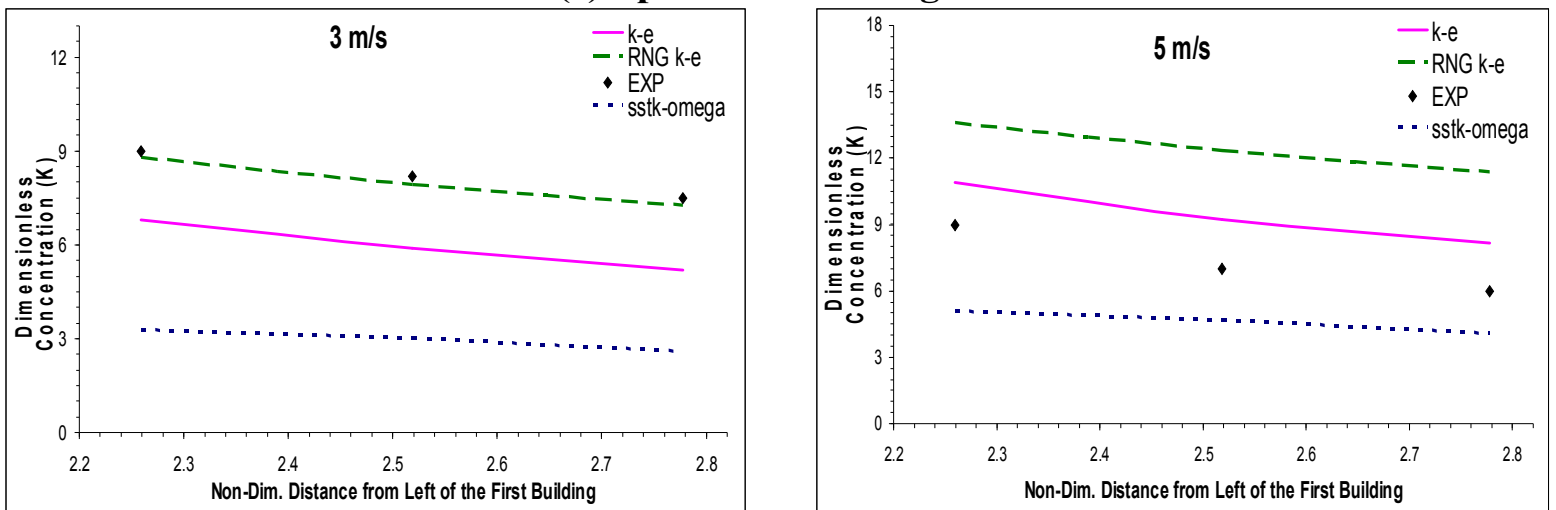

(d) downstream building roof

Fig. 6 comparison between calculated $K$ by numerical models and experiment of Meroney et al. ${ }^{[9]}$ at 3 and $5 \mathrm{~m} / \mathrm{s}$ wind speed 
Wind tunnel measured $\mathrm{C}_{\mathrm{p}}$ distribution in midline surface of the two buildings model is determined and compared with the calculated values by the turbulence k- $\varepsilon$ model Fig. 7 . Along distance on midline path (midline on the surface in 2-D) the figure shows that on the front face of the first building $\mathrm{C}_{\mathrm{p}}$ has its largest value, decreasing rapidly to the smallest negative value at the roof. $\mathrm{C}_{\mathrm{p}}$ slightly increased at the second and third building faces. The comparison shows reasonable agreement between calculated and measured $C_{p}$, thus the $k-\varepsilon$ turbulence model is satisfactory for the simulations of the street canyon models.

Figure 8 shows the air flow and mass fraction of pollution $\left(\mathrm{C}_{\mathrm{O} 2}\right)$ within $1^{\text {st }}, 4^{\text {th }}$, and $8^{\text {th }}$ canyons. It's found that mass fraction of pollution increases with increasing the order number of the canyon due to trapping the pollution inside the street canyon.

In 3-D models four buildings arrangements are studied numerically; 1) first is four cubic buildings arranged to produce a matrix 2 row x 2 columns, 2) second is six cubic buildings arranged to produce one street canyon as a matrix 2 row $x 3$ columns, 3) third is four cubic buildings arranged to produce a matrix 2 row x 4 columns, and 4) fourth is nine cubic buildings arranged to produce a matrix 3 row x 3 columns. In all models, each buildings shape in is chosen to be cube with $6 \mathrm{~cm}$ length. The pollutant concentrations inside the three dimensional domain street canyons are calculated and announced in some vertical and horizontal planes.

A series of flow visualizations were performed in a smoke tunnel. Among them we present here the photo of one street canyon in 2-D with buildings model of the square cross-section of length $1.5 \mathrm{~cm}$ and $\mathrm{w} / \mathrm{h}=1$ is visualized from side view in direction of street canyon in the smoke tunnel with smoked air flow of speed $3 \mathrm{~m} / \mathrm{s}$ see figure $4-\mathrm{a}$. In 3-D models we present here the plan view of; 1) four cubic buildings arranged to produce a matrix 2 row x 2 columns, 2) second is six cubic buildings arranged to produce one street canyon as a matrix 2 row x 3 columns, 3) In all 3-D models, each buildings model shape in is chosen to be cube with $2.5 \mathrm{~cm}$ length.

Figue 9 shows comparison between the flow visualization and numerical simulation of the air flow around two configurations of 4 and 6 buildings at $(\mathrm{y} / \mathrm{h}=0.16)$. It can be shown that a vortex appearance within the street canyon leads to increase the concentrations of the pollution on the leeward faces.

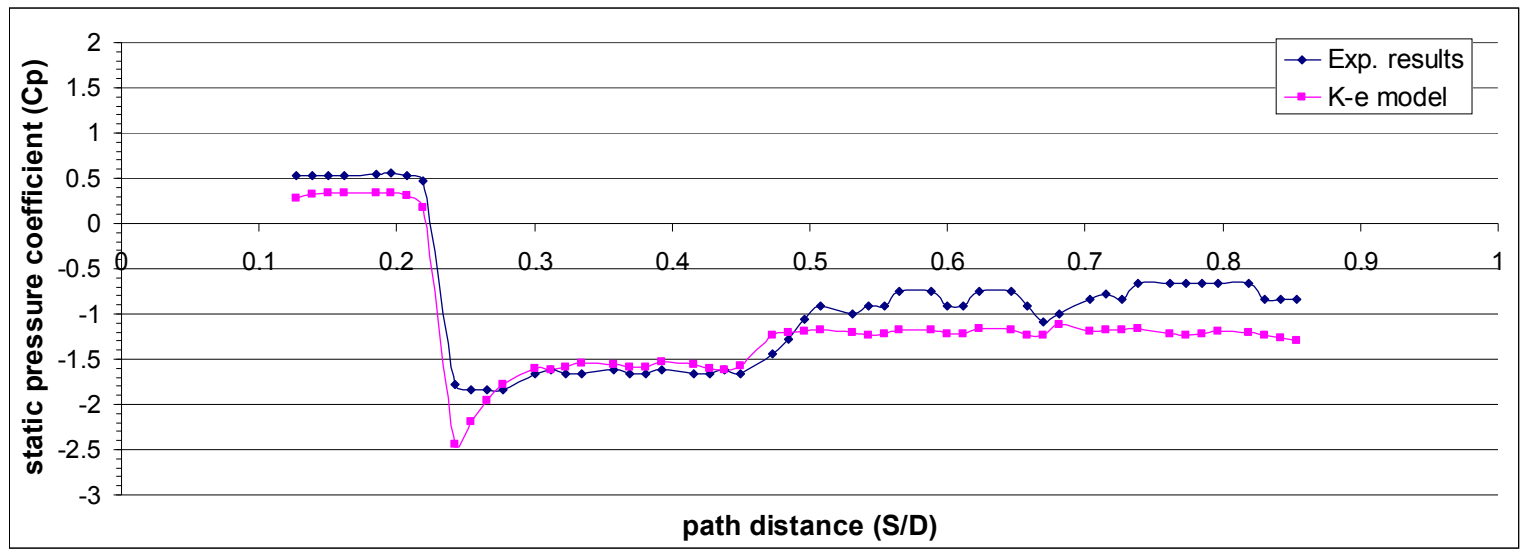

Fig. 7 Calculated and measured $\mathrm{Cp}$ in 2-D vs. path Distance (s/h) 

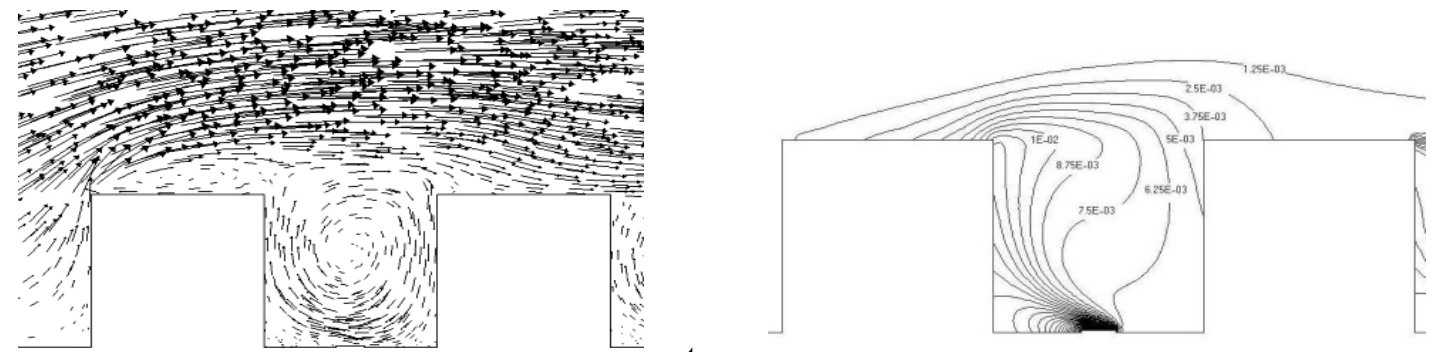

(a) $1^{\text {st }}$ canyon
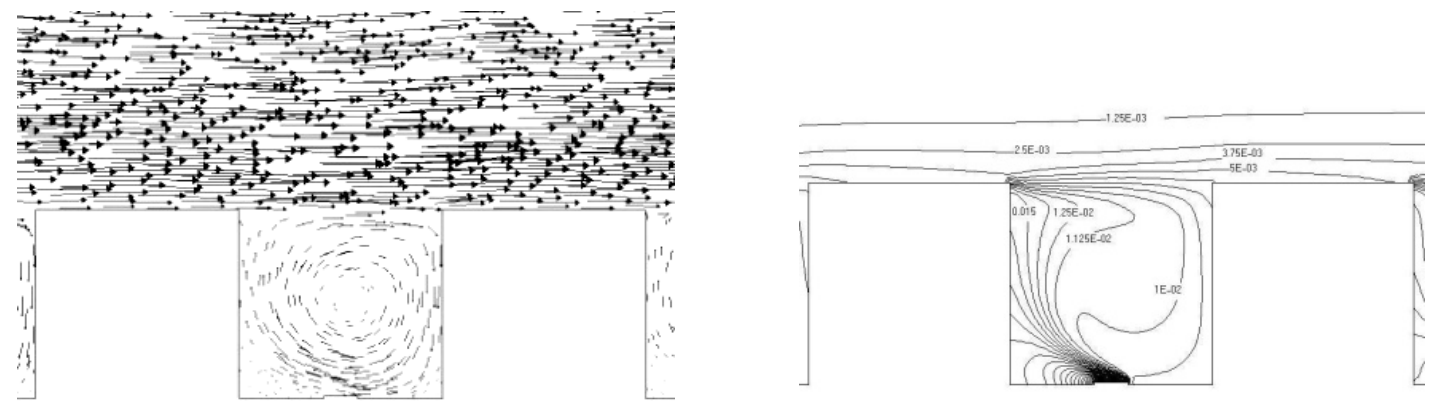

(b) $4^{\text {th }}$ canyon
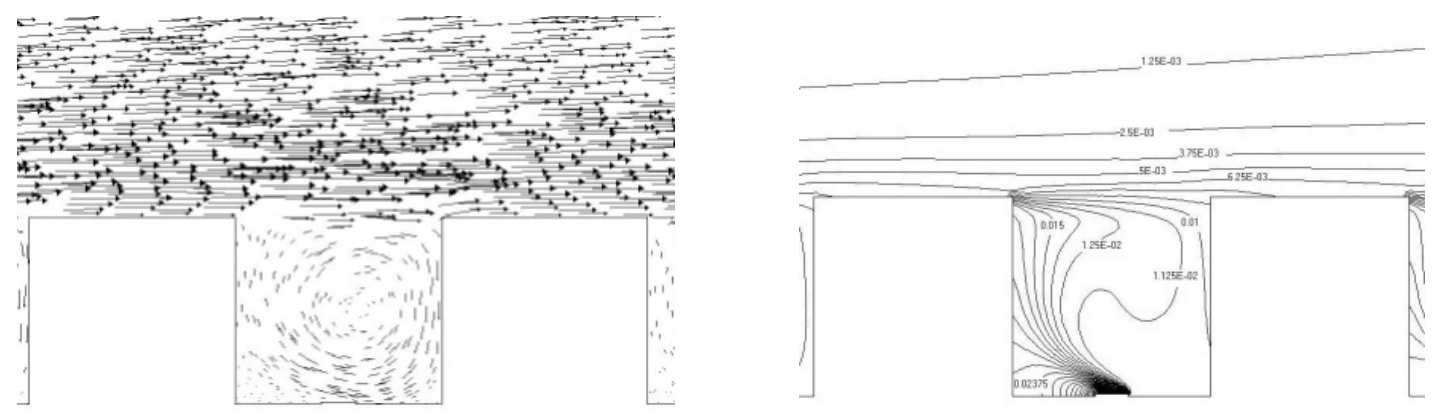

(c) $8^{\text {th }}$ canyon

Fig. 8 Air flow and pollutant concentrations of different street canyon number

Figure 10 shows the pollutant concentration around 4 and 6 and 8 buildings at $(y / h=0.16)$. It's shown that, the vortex in the street leads to increase the concentrations of the pollution on the leeward faces which increased with increasing the number of parallels streets in wind direction. 


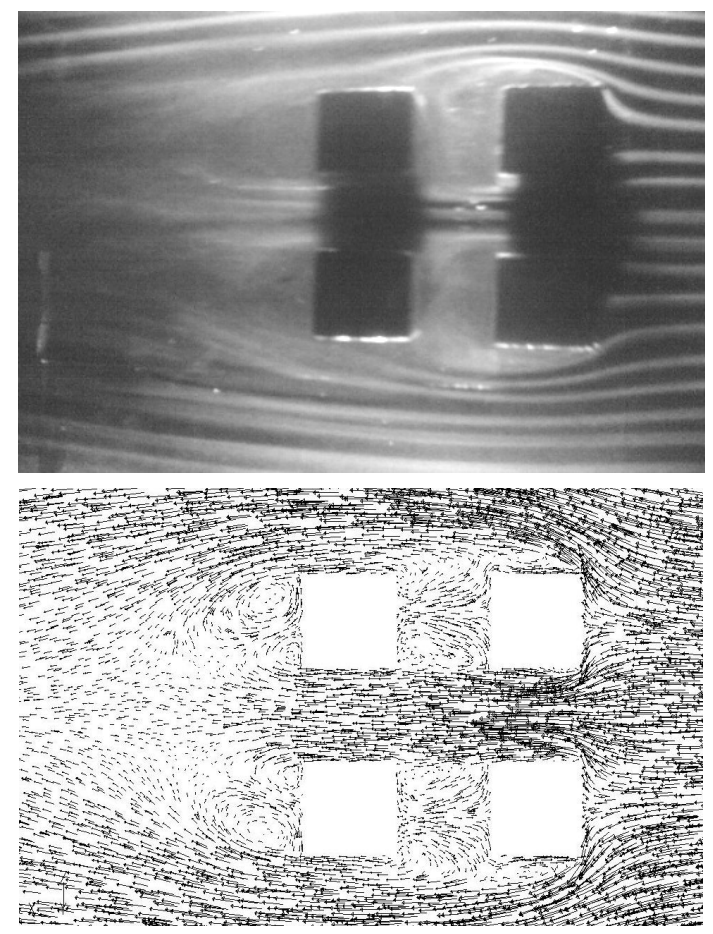

4 buildings arranged $2 \times 2$ matrix

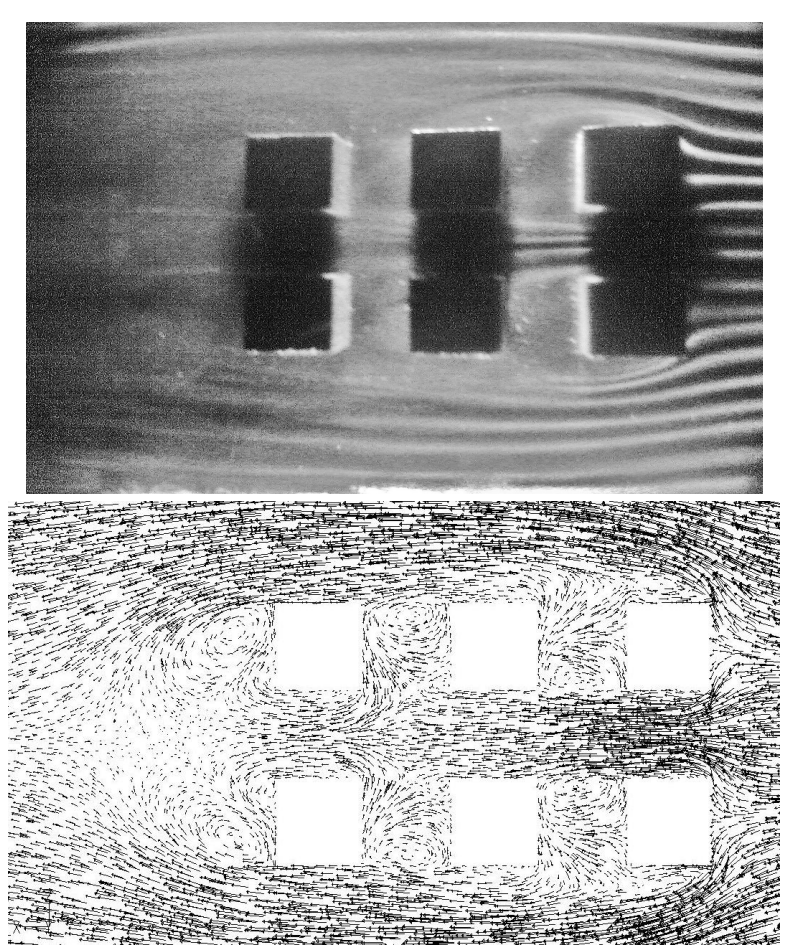

6 buildings arranged $2 \times 3$ matrix

Fig. 9 visualization and numerically simulated flow pattern by $k-\varepsilon$ turbulence model

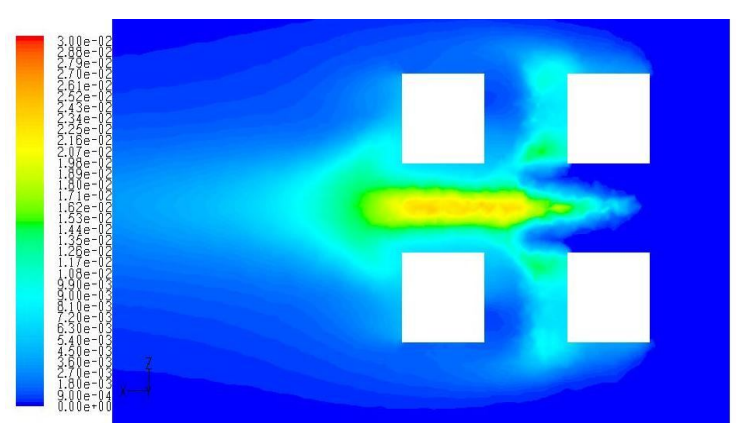

4 buildings arranged

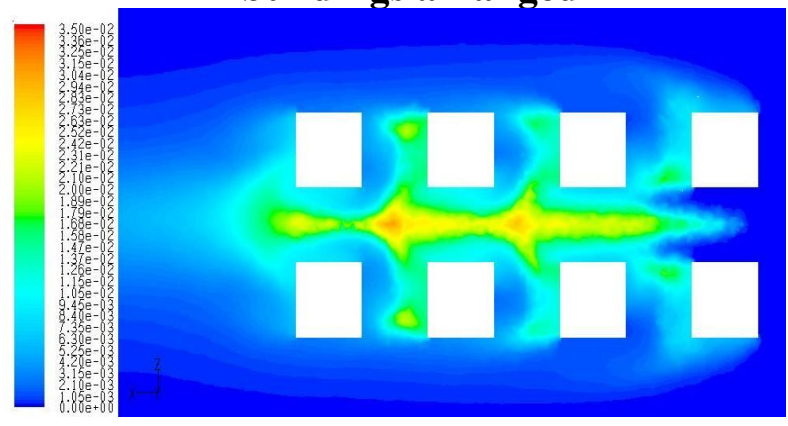

8 buildings arranged

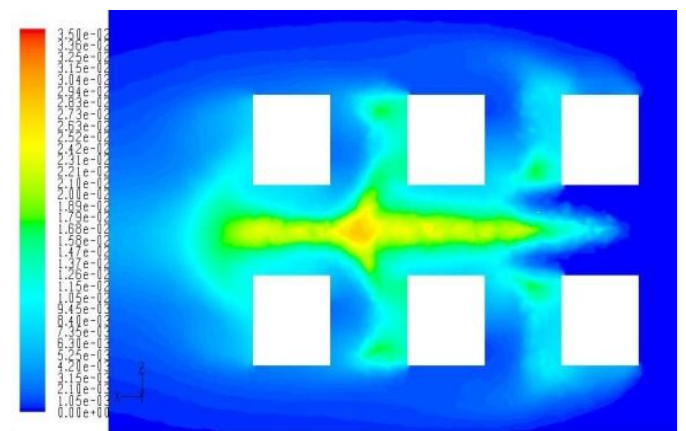

6 buildings arranged

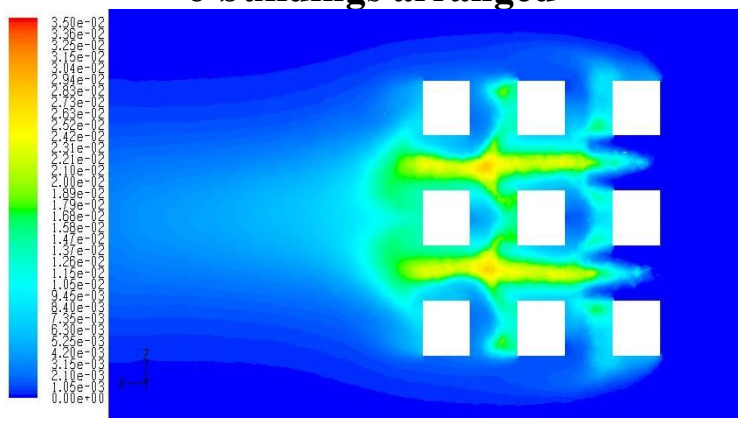

9 buildings arranged

Fig. 10 Pollutant concentrations

\section{Conclusion}

In two and three dimensional domains, effects of different parameters (wind speed, buildings geometries and arrangements, and order of street canyon number in an urban) on simulated vehicle exhausts dispersion within street canyons in various urban models have been investigated. The $\mathrm{k}-\varepsilon$ turbulence model, RNG $\mathrm{k}-\varepsilon$, and sstk- $\omega$ are the used numerical techniques beside a smoke tunnel and wind tunnel measurements. The results can be concluded as: 
1- The predicted dimensionless concentration $\mathrm{K}$ by $\mathrm{k}-\varepsilon$ turbulence model, RNG $\mathrm{k}-\varepsilon$, and sstk- $\omega$ as well as the flow pattern doesn't change significantly with different wind approach velocities.

2- The comparison between visualized and predicted k- $\varepsilon$, RNG k- $\varepsilon$, and sstk- $\omega$ flow pattern in two and three dimensional domain street canyons models shows reasonable agreements.

3- The calculated $k-\varepsilon$ turbulence model and wind tunnel measurement of $C_{p}$ shows that on the front face of the first building $C_{p}$ has its largest value, decreasing rapidly to the smallest negative value at the roof and slightly increased at the second and third building faces.

4- The predicted non-dimensional concentration K of RNG k- $\varepsilon$ shows reasonable agreements with previous experimental work at leeward and windward wall where the sstk- $\omega$ appears underestimates the experiments at leeward and wind ward wall while it show reasonable agreements at upstream and downstream building roof.

5- k- $\varepsilon$ turbulence model appears more reasonable agreement with the experiment of Meroney et al. ${ }^{[9]}$ at low wind speed to predict the non-dimensional concentration $\mathrm{K}$ near walls in comparison with other turbulence models techniques, and overestimates the $\mathrm{K}$ at high wind speeds as well as the other techniques.

6- k- $\varepsilon$ turbulence model applied to multi-street models show that the mass fraction of pollution increases with increasing the order number of the canyon.

7- k- $\varepsilon$ turbulence model applied in all models show that the vortex in the street leads to increase the concentrations of the pollution on the leeward faces.

8- k- $\varepsilon$ turbulence model applied in two and three dimensional domain street canyons models show that the pollutant concentrations at leeward and windward faces decreases with increasing building height.

\section{References}

[1] Ministry of state for environmental affairs, Egyptian environmental affairs agency "Egypt State of the Environment Report 2005" December 2006

[2] Marilena Kampa, Elias Castanas, "Human health effects of air pollution" Environmental pollution, 151 (2008) 362-367

[3] Luke Curtis, William Rea, Patricia Smith-Willis, Ervin Fenyves, Yaqin Pan, "Adverse health effects of outdoor air pollutants" Environment International, 32 (2006) 815-830

[4] Xin Deng, "Economic costs of motor vehicle emissions in China" Transportation Research Part D, 11 (2006) 216-226

[5] J.M. Baldasano, E. Valera, P. Jime'nez, "Air quality data from large cities" The Science of the Total Environment, 307 (2003) 141-165

[6] Xie Xiaomin, Huang Zhen, Wang Jiasong, "The impact of urban street layout on local atmospheric environment" Building and Environment, 41 (2006) 1352-1363

[7] Xiaomin Xie, Zhen Huang, Jia-Song Wang, "Impact of building configuration on air quality in street canyon" Atmospheric Environment, 39 (2005) 4519-4530

[8] Georgios Theodoridis, Nicolas Moussiopoulos, "Influence of building density and roof shape on the wind and dispersion characteristics" Environmental Monitoring and Assessment, 65 (2000) 407-415

[9] Robert N. Meroney, Michel Pavageau, Stilianos Rafailidis, Michael Schatzman, "Study of line source characteristics for 2-D physical modeling of pollutant dispersion in street canyons" J. of Wind Eng. And Industrial Aerodynamics 62 (1996) 37-65

[10] Marcos Sebastiao de Paula Gomes, Andre' Augusto Isnard, Jose' Mauri'cio do Carmo Pinto, "Wind tunnel investigation on the retention of air pollutants in three-dimensional recirculation zones in urban areas" Atmospheric Environment 41 (2007) 4949-4961

[11] Serge Simoens, Michel Ayraulta, James M. Wallace, "The flow across a street canyon of variable width-Part 1: Kinematic description" Atmospheric Environment 41 (2007) 9002-9017 
[12] Christof Gromke, Bodo Ruck, "Influence of trees on the dispersion of pollutants in urban street canyon" Atmospheric Environment 41 (2007) 3287-3302

[13] Kambiz Nazridoust, Goodarz Ahmadi, "Airflow and pollutant transport in street canyons" J. of Wind Eng. And Industrial Aerodynamics 94 (2006) 491-522

[14] John M. Crowther, Abd El-Galeil, A. A. Hassan, "3-D numerical simulation of air pollutant dispersion in street canyons" Water, air, and soil pollution, 2 (2002) 279-295

[15] Wang Jia-song, Huang Zhen, "Numerical study on flow and dispersion in urban street canyons of asymmetrical configurations" Conference of Global Chinese Scholars on Hydrodynamics, 2006, 146-150

[16] A. Kovar-Panskusi, P. Louka, J. F. Sini, E. Savory, M. Czechi, "Influence of geometry on the mean flow within urban street canyons" Water, air, and soil pollution, 2 (2002) 365-380

[17] V.D. Assimakopoulos, H.M. ApSimon, N. Moussiopoulos, "A numerical study of atmospheric pollutant dispersion in different two-dimensional street canyon configurations" Atmospheric Environment, 37 (2003) 4037-4049

[18] Silvana Di Sabatinoa, Riccardo Buccolieria, Beatrice Pulvirentib, Rex Britter "Simulations of pollutant dispersion within idealized urban-type geometries with CFD and integral models" Atmospheric Environment, 41 (2007) 8316-8329

[19] S. Di Sabatino, R. Buccolieri, B. Pulvirenti, R. E. Britter, "Flow and Pollutant Dispersion in Street Canyons using FLUENT and ADMS-Urban" Environ Model Assess, May 2007

[20] Xian XiangLi, Chun-Ho Liu, Dennis Y.C. Leung, "Development of a k- $\varepsilon$ model for the determination of air exchange rates for street canyons" Atmospheric Environment, 39 (2005) 7285-7296

[21] W.J. Coirier, D.M. Fricker, M. Furmanczy and S. Kim, "A Computational Fluid Dynamics Approach for Urban Area Transport and Dispersion Modeling" Environmental Fluid Mechanics, 5 (2005) 443-479

[22] P. Louka, G. Vachon, J. F. Sini, P. G. Mestayer and J. M. Rosant "Thermal effects on the airflow in a street canyon" Water, Air, and Soil Pollution, 2 (2002) 351-364

[23] Xiaomin Xiea, Chun-Ho Liub, Dennis Y.C. Leung, "Impact of building facades and ground heating on wind flow and pollutant transport in street canyons" Atmospheric Environment, 41 (2007) 9030-9049

[24] A. Kovar Panskus, L. Moulinneuf, E. Savory, A. Abdlqari, J.F. Sini, J.M. Rosan, A. Robins, N. Toy, "A Wind Tunnel Investigation of the Influence of Solar-Induced Wall-Heating on the Flow Regime within a Simulated Urban Street Canyon" Water, air, and soil pollution, 2 (2002) 555-571

[25] Launder, B. E., \& Spalding, D. B. "Numerical computation of turbulent flows" Computer Methods in Applied Mechanics and Engineering, 3 (1974) 269-289.

[26] I. A. GAD "Refined Model of Discrete Vortex Method Applied to Sharp Edged Bodies" Journal of Engineering and Applied Sciences, Faculty of Engineering- Cairo University, V. 48-3, June 2000. 